\title{
Establishing a threshold to predict risk of cardiovascular disease from the serum triglyceride and high-density lipoprotein concentrations in persons with spinal cord injury
}

\author{
Michael F. La Fountaine ${ }^{1,2,3,4} \cdot$ Christopher M. Cirnigliaro' ${ }^{1}$ Joshua C. Hobson ${ }^{5}$ Trevor A. Dyson-Hudson ${ }^{6,7}$. \\ Cristin Mc Kenna ${ }^{6,8} \cdot$ Steven C. Kirshblum ${ }^{6,7,8} \cdot$ Ann M. Spungen $\mathbb{1}^{1,9} \cdot$ William A. Bauman ${ }^{1,9,10}$
}

Received: 29 May 2018 / Revised: 20 July 2018 / Accepted: 23 July 2018 / Published online: 8 August 2018

(c) International Spinal Cord Society 2018

\begin{abstract}
Study design Retrospective cohort.

Objective This report identified the serum triglyceride (TG) concentrations in persons with spinal cord injury (SCI) and ablebodied (AB) individuals that the serum high-density lipoprotein cholesterol (HDL-C) equaled $40 \mathrm{mg} / \mathrm{dl}$, a concentration below which is an independent risk factor for coronary artery disease.

Methods Retrospective analysis was performed on 578 participants: 223 with SCI at or proximal to the 4th thoracic vertebrae ( $\uparrow$ T4), 178 with SCI at or distal to the 5th thoracic vertebrae ( $\downarrow$ T5), and 177 AB. Different statistical modeling approaches identified the intersecting serum TG concentration with a serum HDL-C concentration equal to $40 \mathrm{mg} / \mathrm{dl}$. Participants were dichotomized into subgroups by TG concentration exceeding (supra) or falling below (sub) the intersecting value and the TG/HDL-C ratios were compared.

Results Linear regression analysis revealed that the serum TG concentration that intersects with serum HDL-C concentration at $40 \mathrm{mg} / \mathrm{dl}$ was $121 \mathrm{mg} / \mathrm{dl}$ in SCI $\uparrow \mathrm{T} 4$ and $137 \mathrm{mg} / \mathrm{dl}$ in SCI $\downarrow$ T5 group. A ROC curve identified the optimal TG concentration as $115 \mathrm{mg} / \mathrm{dl}$ in SCI $\uparrow \mathrm{T} 4$ and $137 \mathrm{mg} / \mathrm{dl}$ in SCI $\downarrow$ T5 group with the latter concentration being similar to the AB group (e.g., $137 \mathrm{mg} /$ dl). The TG/HDL-C ratios in the respective $\uparrow T 4, \downarrow T 5$, and AB supra and subgroups were similar within each group.

Conclusions A lower TG concentration appears to be associated with dyslipidemia in persons with SCI than AB individuals. These findings should prompt clinicians to screen for and consider instituting lifestyle or pharmacological interventions at lower TG concentrations to reduce risk of CVD.
\end{abstract}

Michael F. La Fountaine

michael.lafountaine@va.gov

1 Department of Veterans Affairs Rehabilitation Research \& Development Service National Center for the Medical Consequences of Spinal Cord Injury, James J. Peters Veterans Affairs Medical Center, Bronx, NY, USA

2 Department of Physical Therapy, School of Health and Medical Sciences, Seton Hall University, South Orange, NJ, USA

3 The Institute for Advanced Study of Rehabilitation and Sports Science, School of Health and Medical Sciences, Seton Hall University, South Orange, NJ, USA

4 Departments of Medical Sciences and Neurology, Hackensack Meridian School of Medicine at Seton Hall University, Nutley, NJ, USA
5 Department of Kinesiology and Applied Physiology, University of Delaware, Newark, DE, USA

6 Kessler Foundation, West Orange, NJ, USA

7 Department of Physical Medicine and Rehabilitation, Rutgers New Jersey Medical School, Newark, NJ, USA

8 Kessler Institute for Rehabilitation, West Orange, NJ, USA

9 Department of Rehabilitation Medicine, Icahn School of Medicine at Mount Sinai, New York, NY, USA

10 Department of Medicine, Icahn School of Medicine at Mount Sinai, New York, NY, USA 


\section{Introduction}

Elevated serum triglyceride (TG) concentrations are a common clinical finding in individuals with increased risk of cardiovascular disease (CVD), abnormal carbohydrate metabolism, insulin resistance, and the metabolic syndrome [1-3]. The National Cholesterol Education Program Adult Treatment Panel (NCEP-ATP III) has previously categorized fasting serum TG concentrations into four different classes with concentration cutoffs at $150 \mathrm{mg} / \mathrm{dl}$ (e.g., borderline high) and $200 \mathrm{mg} / \mathrm{dl}$ (e.g., high) serving as the lower concentration limits for abnormal findings warranting a combination of lifestyle and/or pharmaceutical intervention (s) [4]. The precise concentration at which the serum TG value becomes a predictable marker for CVD has not been defined; however, it has been suggested that the increased risk may be associated with a serum TG concentration $>150 \mathrm{mg} / \mathrm{dl}$ in the general population [5]. The association between elevated serum TG concentrations and CVD risk, or incident cardiac events, remains controversial [6, 7] because the independent effect of elevated serum TG concentrations is generally obviated after statistical adjustments are made to account for serum high-density lipoprotein cholesterol (HDL-C) concentrations [8]. Elevated circulating TG concentrations serve to deplete HDL-C particles through a two-step process $[9,10]$ and, therefore, determine circulating HDL-C concentration [9]. Despite the obvious clinical utility of the serum HDL-C concentrations, the question could be raised as to whether a prime determinant of CVD risk, from a physiological perspective, is the serum TG concentration, rather than the concentration of serum HDL-C, specifically $\leq 40 \mathrm{mg} / \mathrm{dl}$ which is accepted to be an independent risk factor for coronary artery disease (CAD) $[4,11]$. Of note, this latter concentration is often associated with a serum TG concentration $\geq 150 \mathrm{mg} / \mathrm{dl}$ [6].

Spinal cord injury (SCI) results in a complete or partial interruption of neurological function below the level of injury. Cardiovascular morbidity occurs more often than that which is observed in the general population and is a leading cause of death after the first year of injury [12-14]. The most common abnormal lipoprotein finding after SCI is a depressed concentration of serum HDL-C $\leq 40 \mathrm{mg} / \mathrm{dl}$ [15]. Low serum HDL-C concentrations have been associated with borderline high serum TG concentrations [16, 17], but in other articles serum TG concentrations were reported to be in the normal range, or below that of matched ablebodied cohorts [18-24]. The combination of these serum lipid findings (e.g., borderline high TG and low HDL-C concentrations) may be attributed to reduced physical activity or metabolic dysfunction. However, our group previously demonstrated in persons with non-ambulatory, chronic SCI that functional sympathetic nervous system (SNS) innervation to the liver and abdominal tissues had a significant influence on the circulating concentrations of TG-rich lipoproteins [25]. Despite similar visceral abdominal tissue volume and insulin resistance, individuals with a $\mathrm{SCI}$ at or proximal to the 4 th thoracic vertebrae $(\uparrow \mathrm{T} 4) \mathrm{had}$ significantly lower TG concentrations than individuals with an injury at or distal to the 5 th thoracic vertebrae $(\downarrow T 5)$, which is the initial site for the emergence of preganglionic projections to the celiac and superior mesenteric ganglion from the spinal cord that innervates the liver and abdominal viscera $[26,27]$. Thus, it may be speculated that the routinely observed "normal" serum TG concentrations in persons with SCI do not adequately convey the risk for CVD in this cohort when applying screening paradigms that have proven efficacy in the general population [4].

This report explores the relationship between circulating TG and HDL-C concentrations, and more specifically, the serum TG concentrations at which serum HDL-C equals 40 $\mathrm{mg} / \mathrm{dl}$ in SCI cohorts that are assumed to have spared ( $\downarrow \mathrm{T} 5)$ or functionally impaired ( $\uparrow$ T4) SNS innervation to the liver and abdominal tissues. It is hypothesized that, due to the loss of functional SNS innervation to the liver and abdominal tissues, the serum TG concentration at which HDL-C equals $40 \mathrm{mg} / \mathrm{dl}$ will be lower in $\uparrow \mathrm{T} 4$ group than the value of the $\downarrow$ T5 group or that of the general population.

\section{Methods}

A retrospective analysis was performed on data collected in our Center. The inclusive data were retrieved from deidentified or coded databases from the respective parent studies whose aims included cross-sectional analyses addressing lipid concentrations, metabolic dysfunction, or CVD risk in persons with SCI. Available subject data in the parent databases were reviewed to identify those participants with all of the necessary information (e.g., demographic, lipoprotein concentrations) to perform the current analyses. Any subject with missing information were not included in the current analysis. As such, a more comprehensive interrogation of study records to capture additional outcomes that may have been relevant to the current analysis, including cigarette smoking and drinking history/ status or a list of all prescribed medications, was not available.

\section{Participants}

Four hundred-eight unique individuals with chronic SCI (duration of injury $>12$ months) who were non-ambulatory [i.e., American Spinal Injury Association Impairment Scale (AIS) grade A, B, or C] [28] and 197 able-bodied (AB) individuals were identified in the parent databases. Twenty eight (20 AB, $7 \mathrm{SCI})$ participants were excluded from the 
current analysis due to missing data; these exclusions resulted in an inclusive database of 401 persons with SCI and $197 \mathrm{AB}$ controls available to complete the analysis. The parent studies from which the data were collected were performed at the James J. Peters Veterans Affairs Medical Center (JJPVAMC; Bronx, NY) and at the Kessler Institute for Rehabilitation (KIR; West Orange, NJ). SCI participants were recruited from the Spinal Cord Injury Service and outpatient SCI clinics, while AB participants were recruited from the general medicine clinics and community populations (e.g., visitors, outpatients, staff) of the two study sites using IRB approved recruitment flyers and/or referral from clinical sources. To be included in the parent study, and therefore the current analyses, all subjects must have met the same inclusion and exclusion criteria. The current analyses were comprised of men and women with or without SCI who were between the ages 20 and 79 years old. Exclusion criteria included acute medical illness (i.e., were receiving treatment for an active medical condition), receiving treatment for a diagnosed chronic illness (i.e., heart disease, pulmonary disease, diabetes mellitus), or lacked the capacity and/or the inability to provide informed consent. The parent studies from which these data were obtained excluded participants who were taking medications with known direct effects on the study-related outcome measurements included, but was not limited to, all classes of hypolipidemic agents, insulin or peripheral insulin-sensitizing agents, hormone-replacement therapies, or sympathomimetics or their antagonists. An accounting of the participant's specific drug intake and dose were not maintained in the parent studies, and as such were unavailable for this analysis.

Data were collected during a single study visit after participants completed an overnight fast $>6 \mathrm{~h}$ prior to arriving for evaluation and testing between 8 am and $1 \mathrm{pm}$. The study visit included a brief medical history and a venous blood sample for determination of the lipoprotein profile. Body mass index (BMI) was available on all participants and is reported. Venous blood samples collected in the prior studies were analyzed for the serum lipoprotein profile [total cholesterol, TG, HDL-C, and estimated LDL$\mathrm{C}$ ] using the Friedewald formula involving contemporary standards for the respective assay in accordance with standard operating and calibration procedures recommended by the manufacturer of the laboratory device performing the analysis. The serum TG/HDL-C ratio was calculated for each participant.

\section{Statistics}

The SCI cohort was dichotomized by group for the neurological level of injury: $\uparrow \mathrm{T} 4$ or $\downarrow \mathrm{T} 5$ [25]. Separate factorial analysis of variance (ANOVA) were performed to identify the presence of group differences (e.g., $\mathrm{AB}$ vs. SCI, and $\mathrm{AB}$ vs. $\uparrow \mathrm{T} 4$ vs. $\downarrow \mathrm{T} 5)$ in subject demographic, fasting lipid profiles (e.g., total cholesterol, TG, HDL-C, and estimated LDL-C) and TG/HDL-C ratio. Pearson chi-square tests were performed to determine if the groups were significantly different for the number of female participants.

Linear regression analyses were performed for each group (e.g., $\mathrm{AB}, \mathrm{SCI}, \uparrow \mathrm{T} 4$, and $\downarrow \mathrm{T} 5$ ) to identify the regression equation for the relationship between the serum TG and HDL-C concentrations, which was used to calculate the TG concentration at which HDL-C concentration equaled $40 \mathrm{mg} / \mathrm{dl}$. Using a serum HDL-C concentration of $40 \mathrm{mg} / \mathrm{dl}$ as the state variable, a receiver operating characteristic (ROC) curve was used to identify the sensitivity and specificity for the serum TG cutoff values defined as normal (e.g., $150 \mathrm{mg} / \mathrm{dl}$ ), elevated (e.g., $200 \mathrm{mg} / \mathrm{dl}$ ), at the Youden index [YI; intersecting point along the curve that provides the best balance between sensitivity and specificity], and for the TG concentrations identified by linear regression analyses for the $\mathrm{AB}$ control, $\uparrow \mathrm{T} 4$, and $\downarrow \mathrm{T} 5$, and combined SCI groups. In a post-hoc analysis, participants from each group (e.g., AB, $\uparrow \mathrm{T} 4, \downarrow \mathrm{T} 5$ ) were further divided into subgroups based on the serum TG concentrations either exceeding (e.g., supra) or falling below (e.g., sub) the serum TG cutoff value identified by the YI for their respective group. A mixed-model ANOVA was performed to identify the presence of intra- and inter-group differences for the TG/HDL-C ratio. Statistical analyses were completed using IBM SPSS Statistics 24 (IBM, Armonk, NY, USA) and regression lines for the relationship between TG and HDLC concentrations were plotted with GraphPad Prism (version 5.04 for Windows, GraphPad Software, San Diego, CA, USA). An a priori level of significance was set at $p \leq$ 0.05 .

\section{Results}

Demographic, anthropometric, and lipid concentrations for each of the primary and SCI subgroups are provided (Table 1). There were no statistical differences found between the SCI and $\mathrm{AB}$ groups for the demographic characteristics. However, upon separation into a subgroup based on the neurological level of injury (e.g., $\uparrow \mathrm{T} 4, \downarrow T 5$ ), several differences between the control group and the respective SCI subgroups emerged (e.g., BMI, and serum total cholesterol, LDL-C and HDL-C concentrations). Statistically significant differences between the $\uparrow \mathrm{T} 4$ and $\downarrow \mathrm{T} 5$ groups also became apparent (e.g., BMI, serum total cholesterol concentration), but in exploratory statistical modeling, these group differences were found to not have a significant effect on the prediction models and were not included. 
Table 1 Demographic and serum lipid concentrations by group

\begin{tabular}{|c|c|c|c|c|c|c|c|}
\hline & \multirow[b]{2}{*}{ Control } & \multirow[b]{2}{*}{ All SCI } & \multirow[b]{2}{*}{$\uparrow \mathrm{T} 4$} & \multicolumn{2}{|l|}{ SCI vs. control } & \multicolumn{2}{|c|}{$\uparrow \mathrm{T} 4$ vs. $\downarrow$ T5 vs. control } \\
\hline & & & & $\downarrow \mathrm{T} 5$ & $p$-value & $p$-value & Post hoc \\
\hline$n$ & 177 & 401 & 223 & 178 & & & \\
\hline Age (yrs) & $47 \pm 13$ & $48 \pm 13$ & $47 \pm 13$ & $48 \pm 14$ & NS & NS & - \\
\hline $\operatorname{BMI}\left(\mathrm{kg} / \mathrm{m}^{2}\right)$ & $27.4 \pm 5.0$ & $25.7 \pm 5.1$ & $25.1 \pm 5.0^{*, \dagger}$ & $26.4 \pm 5.2$ & $<0.0001$ & $<0.0001$ & $\begin{array}{l}{ }^{*} p<0.05 ; \uparrow \mathrm{T} 4 \text { vs. control; } \\
{ }^{\dagger} p<0.05: \uparrow \mathrm{T} 4 \text { vs. } \downarrow \mathrm{T} 5\end{array}$ \\
\hline DOI (yrs) & - & $17 \pm 12$ & $17 \pm 13$ & $17 \pm 13$ & - & NS & - \\
\hline Gender $(\mathrm{M} / \mathrm{F})$ & $165 / 12$ & $380 / 22$ & $215 / 9$ & $165 / 13$ & NS & NS & - \\
\hline Total cholesterol (mg/dl) & $199 \pm 44$ & $181 \pm 38$ & $176 \pm 35^{*}, \dagger$ & $187 \pm 42^{\ddagger}$ & $p<0.0001$ & $p<0.0001$ & $\begin{array}{l}{ }^{*} p<0.05 ; \uparrow \mathrm{T} 4 \text { vs. control; } \\
{ }^{\dagger} p<0.05: \uparrow \mathrm{T} 4 \text { vs. } \downarrow \mathrm{T} 5 \\
{ }^{\ddagger} p<0.05: \downarrow \mathrm{T} 5 \text { vs. control }\end{array}$ \\
\hline LDL-C (mg/dl) & $127 \pm 40$ & $115 \pm 33$ & $112 \pm 32 *$ & $119 \pm 34$ & $p<0.0001$ & $p<0.0001$ & ${ }^{*} p<0.05 ; \uparrow \mathrm{T} 4$ vs. control; \\
\hline HDL-C (mg/dl) & $47 \pm 13$ & $40 \pm 11^{\dagger}$ & $40 \pm 11^{*}$ & $41 \pm 10$ & $p<0.0001$ & $p<0.0001$ & $\begin{array}{l}{ }^{*} p<0.001 ; \uparrow T 4 \text { vs. control; } \\
{ }^{\dagger} p<0.001: \downarrow T 5 \text { vs. control }\end{array}$ \\
\hline Triglyceride $(\mathrm{mg} / \mathrm{dl})$ & $124 \pm 72$ & $127 \pm 79$ & $121 \pm 77$ & $135 \pm 80$ & NS & NS & - \\
\hline TG/HDL-C ratio & $3.0 \pm 2.6$ & $3.6 \pm 2.8^{*}$ & $3.5 \pm 2.8$ & $3.7 \pm 2.9$ & $<0.05$ & 0.09 & $* p<0.05 ;$ SCI vs. control \\
\hline
\end{tabular}

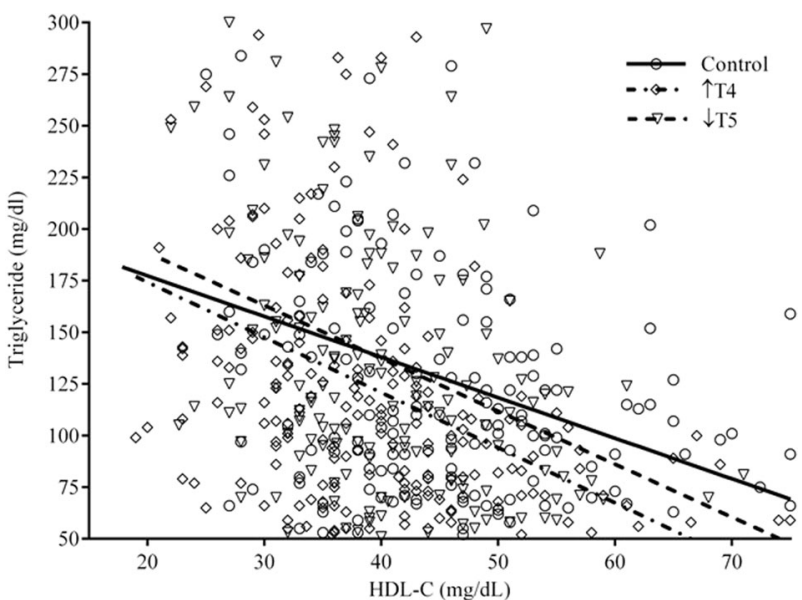

Fig. 1 Serum triglyceride concentrations were plotted against the serum HDL-C concentrations for the $\uparrow T 4, \downarrow T 5$, and able-bodied control groups

To test the hypotheses that the serum TG concentration at which serum HDL-C concentration equals $40 \mathrm{mg} / \mathrm{dl}$ occurs at a lower threshold in persons with SCI than controls, the variables were plotted to solve for y (serum TG concentrations; Fig. 1). Linear regression analyses were performed to identify the regression equation for each group (e.g., AB, SCI, $\uparrow T 4$, and $\downarrow T 5$ ), and the analysis revealed a significant relationship $(p<0.0001)$ between serum TG and HDL-C for each group (Fig. 2). Using regression equations, the serum TG concentration equal to a HDL-C concentration of $40 \mathrm{mg} / \mathrm{dl}$ was calculated for the combined SCI group and separately for the $\uparrow \mathrm{T} 4$ and $\downarrow \mathrm{T} 5$ subgroups. The respective TG concentrations from ROC curve analyses for these groups were determined to be 130,115 , and $137 \mathrm{mg} /$ $\mathrm{dl}$, respectively.

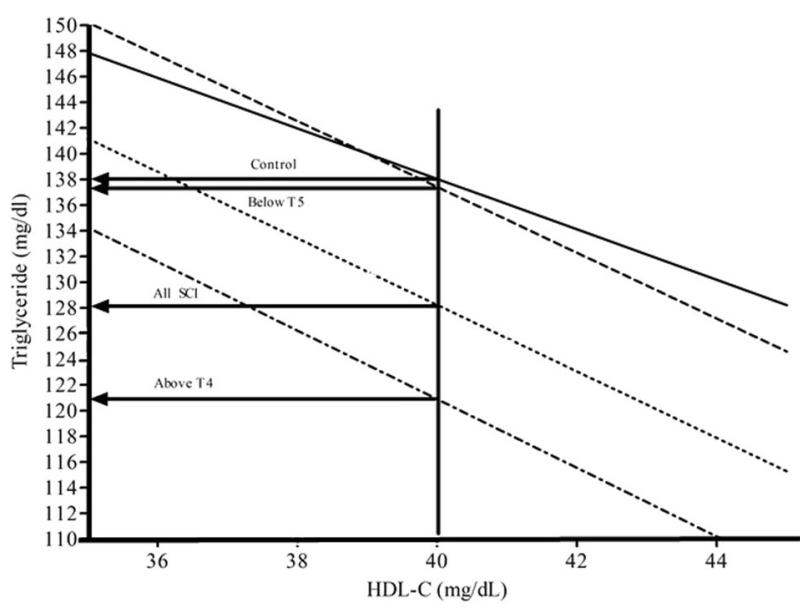

Fig. 2 Serum triglyceride concentrations were plotted against the serum HDL-C concentrations. The vertical line at the HDL-C concentration of $40 \mathrm{mg} / \mathrm{dl}$ permit the identification of the corresponding serum TG concentration for each group and SCI subgroup. Individual participant data are redacted and the range of the $\mathrm{x}$ and $\mathrm{y}$ axis narrowed to enhance the visualization of the respective intersections of data. The line of regression for each group was significant $(p<0.0001)$. Regression equations for each group are as follows: control: $\mathrm{TG}=217$ -1.97 (HDL-C); All SCI: TG $=232-2.59$ (HDL-C); $\uparrow$ T4: TG $=228$ -2.67 (HDL-C); $\downarrow$ T5: TG $=240-2.56$ (HDL-C)

With serum HDL-C concentration $(40 \mathrm{mg} / \mathrm{dl})$ entered as the state variable, ROC curves were used to identify the sensitivity and specificity for serum TG cutoff values defined as normal (e.g., $150 \mathrm{mg} / \mathrm{dl}$ ), elevated (e.g., $200 \mathrm{mg} /$ $\mathrm{dl}$ ), at the YI, and for the serum TG concentrations identified by linear regression analyses (Table 2). As hypothesized, the sensitivity (\%) for each group improved after the statistically modeled values for the intersecting concentrations between serum TG and HDL-C were entered. The most notable improvement in sensitivity (\%) was observed 


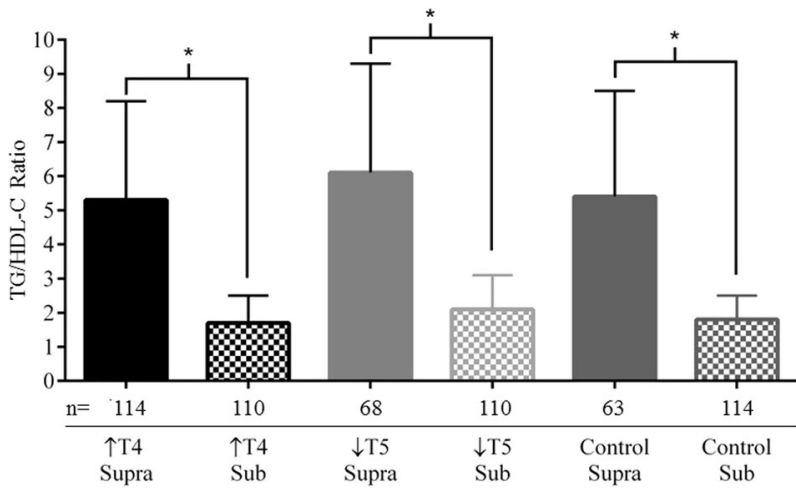

Fig. 3 TG/HDL-C ratio for groups based on TG concentrations either exceeding (e.g., supra) or falling below (e.g., sub) their respective group's TG cutoff value identified by the YI. For each intra-group comparison, the supra-threshold groups had a significantly greater TG/ HDL-C ratio than their sub-threshold counterpart $(* p<0.0001)$. No differences emerged in the inter-group comparisons for supra- or subthreshold groups

in the $\uparrow \mathrm{T} 4$ group for which there was an approximate $65 \%$ increase in the prediction of sensitivity (e.g., 36-59\%) when the model was adjusted to the serum TG concentration identified from the YI of $115 \mathrm{mg} / \mathrm{dl}$ compared to that from the conventional threshold serum TG concentration of 150 $\mathrm{mg} / \mathrm{dl}$. The $\downarrow \mathrm{T} 5$ group demonstrated a $25 \%$ improvement of sensitivity (e.g., 40-50\%) when using the serum TG concentration that was co-identified by the linear regression analyses and YI $(137 \mathrm{mg} / \mathrm{dl})$. Improvements in sensitivity were demonstrated in the $\mathrm{AB}$ group after accounting for the statistically modeled findings. The TG/HDL-C ratio was evaluated between groups based on the TG concentration either exceeding (e.g., supra) or falling below (e.g., sub) the serum TG cutoff value for each group identified by the YI. In post-hoc analyses, the supra-threshold groups for each intra-group comparison had a significantly greater TG/ HDL-C ratio than the sub-threshold counterpart $(p<0.0001$; Fig. 3); no significant differences emerged from the intergroup comparisons by supra- or sub-thresholds for the SCI (total, $\uparrow \mathrm{T} 4$, and $\downarrow \mathrm{T} 5$ ) and $\mathrm{AB}$ groups (Fig. 3).

\section{Discussion}

There are several novel and clinically relevant observations from the findings in this report. Most notably, the serum TG concentration that intersect with a serum HDL-C of $40 \mathrm{mg} /$ $\mathrm{dl}$, the value recognized as an independent risk factor for CAD [4, 11], is lower in persons with SCI than the value observed in the general population (e.g., $150 \mathrm{mg} / \mathrm{dl}$ ) [4, 29] and our $A B$ group $(137 \mathrm{mg} / \mathrm{dl})$. The shift of intersecting point had the most significant impact on the $\uparrow \mathrm{T} 4$ subgroup. In the $\uparrow \mathrm{T} 4$ cohort, the YI from the ROC curve analysis identified a TG concentration of $115 \mathrm{mg} / \mathrm{dl}$ as the value that 
provided the optimal TG concentration to detect or exclude a dyslipidemia characterized by an absolutely low HDL-C concentration. The $\uparrow \mathrm{T} 4$ cohort has an impairment or ablation of functional SNS innervation to the liver and abdominal viscera $[25,30,31]$ and may result from a reduced hepatic synthesis or mobilization and utilization of TG from adipose sources [32-34]. Our findings from the ROC analysis suggests that a serum TG concentration $>115$ $\mathrm{mg} / \mathrm{dl}$ in persons with SCI $\uparrow \mathrm{T} 4$ should be considered the threshold value above which the level of serum TG is elevated, especially in those in whom the serum HDL-C concentrations are $\leq 40 \mathrm{mg} / \mathrm{dl}$. The intersecting serum TG concentration with the serum HDL-C concentration of 40 $\mathrm{mg} / \mathrm{dl}$ was determined to be $137 \mathrm{mg} / \mathrm{dl}$ in the SCI $\downarrow \mathrm{T} 5$ group, which was lower than the serum TG concentration reported for the general population of $150 \mathrm{mg} / \mathrm{dl}$ [4, 29], but was similar to our $\mathrm{AB}$ participants who were comprised of a mostly veteran population.

In the post-hoc analysis, each group or subgroup was dichotomized by the YI determined serum TG concentrations that exceeded (supra) or was less than (sub) the determined threshold value; intra-cohort comparisons were performed for the TG/HDL-C ratio, which has been reported in the literature as a predictor for both hyperinsulinemia (>3.5) [35] and atherogenic risk (>4.0) [36]. The supra TG threshold subgroups within each primary group (e.g., AB, $\uparrow T 4, \downarrow T 5)$ were found to have a statistically significant elevation of the TG/HDL-C ratio with an accompanying heightened risk for CVD compared to the respective subthreshold group [35, 36]. As anticipated, and supporting our statistical modeling approaches, the TG/HDL-C ratio across the respective supra- and sub-threshold groups were similar. Had our original hypothesis and statistical modeling been incorrect, the TG/HDL-C ratios would have been more dissimilar than those observed herein. Thus, the TG/HDL-C ratio in supra- and sub-threshold groups lend support to our hypothesis that an adverse serum TG concentration occurs at a lower concentration in persons with SCI, especially those with SCI $\uparrow$ T4.

By using the serum HDL-C concentration as the arbiter of CVD risk, several factors, including soft tissue body composition, insulin resistance, and disorders of carbohydrate handling, are addressed. Although it may be possible to tease out the partial contribution of each to serum HDL-C, our approach essentially obviates the need to do so, in order to permit the identification of the serum TG concentration for a particular cohort to more appropriately stratify the risk of CVD. Although in our previous report the role for increasing visceral adiposity and insulin resistance on the circulating TG concentrations was assessed [25], the interaction between serum TG and HDL-C concentrations was not determined. As such, we cannot exclude the possibility of the influence of increasing adipose tissue volume, where it is compartmentalized (e.g., visceral versus subcutaneous), or the degree of insulin resistance of each participant on the reported outcomes in the current retrospective analyses. There were minor differences in BMI values across the groups, but the group means indicated that the $\mathrm{SCI}$ and $\mathrm{AB}$ cohorts were both overweight and it was found not to be a significant contributor to the models.

The challenge in applying the NCEP [4], ACC/AHA guidelines [37], or that of cardiometabolic risk [38] to individuals with $\mathrm{SCI}$ is that the characteristic lipid profile includes an extremely depressed serum HDL-C concentration, with values $<\sim 40 \mathrm{mg} / \mathrm{dl}$ observed in about half, $<35$ $\mathrm{mg} / \mathrm{dl}$ occurring in about one-third, and $<30 \mathrm{mg} / \mathrm{dl}$ in about one-fifth of the population $[15,39]$. The serum TG concentrations have been reported to be mildly elevated or normal by conventional standards ( $\mathrm{TG} \geq 150 \mathrm{mg} / \mathrm{dl}$ ), and LDL-C are often within the normal range and present with a similar distribution to that of the general population $[15,17$, 40, 41]. As such, initiating therapy with a statin is not recommended by the current guidelines for most individuals with SCI. Prescribing physical activity or dietary intervention(s) is challenging in $A B$ individuals, and one would anticipate that it would not be any easier in those with a severe physical disability. The difficulties of compliance with an exercise program being appreciated, the volume of exercise necessary to induce favorable changes to the lipoprotein profile would be logistically difficult for most persons with SCI. However, structured and routine exercise programs have been demonstrated to be efficacious when performed [19, 42, 43].

NCEP guidelines recommend that individuals with elevated TG concentrations (e.g., $\geq 200 \mathrm{mg} / \mathrm{dl}$ ) consider the introduction of a peroxisome proliferator-activated receptor $\alpha$ (PPAR- $\alpha$; fibric acid) to lower TG concentration [44] or nicotinic acid to raise HDL-C concentration [4]. As of this report, no clinical trial data has been published to demonstrate the potential efficacy of a PPAR- $\alpha$ agent to lower the serum TG concentration in persons with SCI. Based on the NCEP guidelines, an individual with higher levels of SCI would not be considered eligible for this type of intervention because of lower serum TG concentrations; from evidence presented herein in persons with SCI, fibric acid derivatives should be investigated as an appropriate therapeutic option to intervene at our revised lower serum TG concentrations. A 48-week randomized, single-blind, placebo controlled clinical trial with nicotinic acid (e.g., Niaspan) was performed in persons with tetraplegia and found to be effective at increasing HDL-C by $\sim 25 \%$ and reducing TG by $\sim 13 \%$ [45]. Unfortunately, no further work has been reported to extend these findings, such as the benefit to reduce atherosclerotic burden (e.g., carotid intimal medial thickness) or to reduce CVD events. Thus, the paucity of clinical trial data in the SCI population provides the 
opportunity to evaluate the efficacy of interventions to favorably modify the lipoprotein profile and, by doing so, mitigate CVD risk.

\section{Study limitations}

Specific details of the subject history that may have influenced the data were not available, such as cigarette smoking, and alcohol intake. The effects of these potential confounders could not be controlled for in our analysis. While these findings demonstrate the utility of the ROC curve to determine the sensitivity and specificity across a range of different $\mathrm{TG}$ cutoff values to accurately diagnose HDL-C concentrations $\leq 40 \mathrm{mg} / \mathrm{dl}$, the moderate strength of the TG and HDL-C relationship presented limits the accuracy of all the predictive models used as demonstrated by AUC values that ranged from 0.65 to 0.72 . Future studies are needed in a comparable sample size to that described herein with the ability to assess the value of adding multiple predictors for a stronger model that can account for a greater degree of the variance in the prediction of TG cutoff values.

\section{Conclusion}

The serum TG concentration at which the serum HDL-C concentration intersects with $40 \mathrm{mg} / \mathrm{dl}$ was found to be lower in persons with SCI than that reported in the general population. Our statistical modeling suggests that the serum TG concentration threshold associated with increased risk of CVD in individuals with SCI $\uparrow$ T4 is $115 \mathrm{mg} / \mathrm{dl}$, and in those with SCI $\downarrow$ T5 is $137 \mathrm{mg} / \mathrm{dl}$. Use of these TG concentrations thresholds to dichotomize groups produced TG/ HDL-C ratios that were comparable across the cohorts and markedly elevated compared to those who were below the threshold value. These findings support our hypothesis that a relatively lower serum TG concentration more accurately identifies risk of CVD in persons with SCI than that which has been accepted for the general population. With these revised threshold values for the serum TG concentration, clinicians should be in a more informed position to better identify individuals with SCI who are at increased risk of CVD, and then to consider instituting appropriate dietary, exercise, and/or pharmacological interventions to reduce the morbidity of metabolic dysfunction and accompanying heightened risk of CVD.

Acknowledgements This work was supported by the Veterans Affairs Rehabilitation Research and Development Service (\#B2020-C).

Author contributions MFL: conceptualization, formal analysis, completion of investigation, project administration, preparation of draft and final draft approval; CMC: formal analysis, completion of investigation, project administration, preparation of draft and final draft approval; JCH: completion of investigation, project administration, final draft approval; TAD: completion of investigation, preparation of draft, final draft approval; CM: completion of investigation, final draft approval; SCK: completion of investigation, project administration, preparation of draft, final draft approval; AMS: funding acquisition, formal analysis, preparation of draft, final draft approval; WAB: conceptualization, formal analysis, funding acquisition, project administration, formal analysis, final draft approval.

Funding This work was supported by the Department of Veterans Affairs, Veterans Health Administration, Rehabilitation Research and Development Service National Center for the Medical Consequences of Spinal Cord Injury (\#B2020-C). The funders had no decision to publish, or preparation of the manuscript.

\section{Compliance with ethical standards}

Conflict of interest The authors declare that they have no conflict of interest.

Informed consent The parent protocols were carriled out with approval from the Institutional Review Board of the James J. Peters VA Medical Center and Kessler Institute for Rehabilitation. All subjects provided written informed consent to participate.

\section{References}

1. Reiner Z. Hypertriglyceridaemia and risk of coronary artery disease. Nat Rev Cardiol. 2017;14:401-11.

2. Swarup S, Zeltser R. Metabolic syndrome. Treasure Island (FL): StatPearls; 2017.

3. Wu L, Parhofer KG. Diabetic dyslipidemia. Metabolism. 2014;63:1469-79.

4. National Cholesterol Education Program (NCEP) Expert Panel on Detection, Evaluation, and Treatment of High Blood Cholesterol in Adults (Adult Treatment Panel III). Third Report of the National Cholesterol Education Program (NCEP) Expert Panel on Detection, Evaluation, and Treatment of High Blood Cholesterol in Adults (Adult Treatment Panel III) final report. Circulation. 2002;106:3143-421.

5. Tenenbaum A, Klempfner R, Fisman EZ. Hypertriglyceridemia: a too long unfairly neglected major cardiovascular risk factor. Cardiovasc Diabetol. 2014;13:159.

6. Miller M, Stone NJ, Ballantyne C, Bittner V, Criqui MH, Ginsberg HN, et al. Triglycerides and cardiovascular disease: a scientific statement from the American Heart Association. Circulation. 2011;123:2292-333.

7. Nordestgaard BG, Varbo A. Triglycerides and cardiovascular disease. Lancet. 2014;384:626-35.

8. Emerging Risk Factors C, Di Angelantonio E, Sarwar N, Perry P, Kaptoge S, Ray KK, et al. Major lipids, apolipoproteins, and risk of vascular disease. JAMA. 2009;302:1993-2000.

9. Otvos JD. Measurement of lipoprotein subclass profiles by nuclear magnetic resonance spectroscopy. Clin Lab. 2002;48:171-80.

10. Cromwell WC, Otvos JD, Keyes MJ, Pencina MJ, Sullivan L, Vasan RS, et al. LDL particle number and risk of future cardiovascular disease in the Framingham Offspring Study-implications for LDL management. J Clin Lipidol. 2007;1:583-92.

11. Gotto AM Jr, Brinton EA. Assessing low levels of high-density lipoprotein cholesterol as a risk factor in coronary heart disease: a working group report and update. J Am Coll Cardiol. 2004;43:717-24. 
12. DeVivo MJ, Shewchuk RM, Stover SL, Black KJ, Go BK. A cross-sectional study of the relationship between age and current health status for persons with spinal cord injuries. Paraplegia. 1992;30:820-7.

13. Garshick E, Kelley A, Cohen SA, Garrison A, Tun CG, Gagnon $\mathrm{D}$, et al. A prospective assessment of mortality in chronic spinal cord injury. Spinal Cord. 2005;43:408-16.

14. Wahman K, Nash MS, Lewis JE, Seiger A, Levi R. Increased cardiovascular disease risk in Swedish persons with paraplegia: the Stockholm spinal cord injury study. J Rehabil Med. 2010;42:489-92.

15. Gilbert O, Croffoot JR, Taylor AJ, Nash MS, Schomer K, Groah SL. Serum lipid concentrations among persons with spinal cord injury-a systematic review and meta-analysis of the literature. Atherosclerosis. 2014;232:305-12.

16. Tharion G, Prasad KR, Gopalan L, Bhattacharji S. Glucose intolerance and dyslipidaemias in persons with paraplegia and tetraplegia in south India. Spinal Cord. 1998;36:228-30.

17. Zlotolow SP, Levy E, Bauman WA. The serum lipoprotein profile in veterans with paraplegia: the relationship to nutritional factors and body mass index. J Am Paraplegia Soc. 1992; 15:158-62.

18. Bauman WA, Spungen AM. Disorders of carbohydrate and lipid metabolism in veterans with paraplegia or quadriplegia: a model of premature aging. Metabolism. 1994;43:749-56.

19. de Groot S, Dallmeijer AJ, Post MW, Angenot EL, van der Woude LH. The longitudinal relationship between lipid profile and physical capacity in persons with a recent spinal cord injury. Spinal Cord. 2008;46:344-51.

20. Maki KC, Briones ER, Langbein WE, Inman-Felton A, Nemchausky B, Welch M, et al. Associations between serum lipids and indicators of adiposity in men with spinal cord injury. Paraplegia. 1995;33:102-9.

21. Wang YH, Chen SY, Wang TD, Hwang BS, Huang TS, Su TC. The relationships among serum glucose, albumin concentrations and carotid atherosclerosis in men with spinal cord injury. Atherosclerosis. 2009;206:528-34.

22. Zhong YG, Levy E, Bauman WA. The relationships among serum uric acid, plasma insulin, and serum lipoprotein levels in subjects with spinal cord injury. Horm Metab Res. 1995;27:283-6.

23. Bauman WA, Adkins RH, Spungen AM, Herbert R, Schechter C, Smith $\mathrm{D}$, et al. Is immobilization associated with an abnormal lipoprotein profile? Observations from a diverse cohort. Spinal Cord. 1999;37:485-93.

24. Bauman WA, Spungen AM, Wang J, Pierson RN Jr.. The relationship between energy expenditure and lean tissue in monozygotic twins discordant for spinal cord injury. J Rehabil Res Dev. 2004;4:1-8.

25. La Fountaine MF, Cirnigliaro CM, Kirshblum SC, McKenna C, Bauman WA. Effect of functional sympathetic nervous system impairment of the liver and abdominal visceral adipose tissue on circulating triglyceride-rich lipoproteins. PLoS ONE. 2017;12: e0173934.

26. Shimazu T. Innervation of the liver and glucoregulation: roles of the hypothalamus and autonomic nerves. Nutrition. 1996;12:65-6.

27. Jungermann K, Stumpel F. Role of hepatic, intrahepatic and hepatoenteral nerves in the regulation of carbohydrate metabolism and hemodynamics of the liver and intestine. Hepatogastroenterology. 1999;46(Suppl 2):1414-7.

28. Kirshblum SC, Burns SP, Biering-Sorensen F, Donovan W, Graves DE, Jha A, et al. International standards for neurological classification of spinal cord injury (revised 2011). J Spinal Cord Med. 2011;34:535-46.

29. Heiss G, Tamir I, Davis CE, Tyroler HA, Rifkand BM, Schonfeld $\mathrm{G}$, et al. Lipoprotein-cholesterol distributions in selected North American populations: the lipid research clinics program prevalence study. Circulation. 1980;61:302-15.

30. Carreno FR, Seelaender MC. Liver denervation affects hepatocyte mitochondrial fatty acid transport capacity. Cell Biochem Funct. 2004;22:9-17.

31. Tavares FL, Seelaender MC. Hepatic denervation impairs the assembly and secretion of VLDL-TAG. Cell Biochem Funct. 2008;26:557-65.

32. Holm C. Molecular mechanisms regulating hormone-sensitive lipase and lipolysis. Biochem Soc Trans. 2003;31(Pt 6):1120-4.

33. Arner P. Not all fat is alike. Lancet. 1998;351:1301-2.

34. Lafontan M, Langin D. Lipolysis and lipid mobilization in human adipose tissue. Prog Lipid Res. 2009;48:275-97.

35. Li C, Ford ES, Meng YX, Mokdad AH, Reaven GM. Does the association of the triglyceride to high-density lipoprotein cholesterol ratio with fasting serum insulin differ by race/ethnicity? Cardiovasc Diabetol. 2008;7:4.

36. da Luz PL, Favarato D, Faria-Neto JR Jr., Lemos P, Chagas AC. High ratio of triglycerides to HDL-cholesterol predicts extensive coronary disease. Clinics. 2008;63:427-32.

37. Stone NJ, Robinson JG, Lichtenstein AH, Bairey Merz CN, Blum $\mathrm{CB}$, Eckel RH, et al. 2013 ACC/AHA guideline on the treatment of blood cholesterol to reduce atherosclerotic cardiovascular risk in adults: a report of the American College of Cardiology/American Heart Association Task Force on Practice Guidelines. J Am Coll Cardiol. 2014;63(25 Pt B):2889-934.

38. Nash MS, Tractenberg RE, Mendez AJ, David M, Ljungberg IH, Tinsley EA, et al. Cardiometabolic syndrome in people with spinal cord injury/disease: guideline-derived and nonguideline risk components in a pooled Sample. Arch Phys Med Rehabil. 2016;97:1696-705.

39. Bauman WA, Spungen AM, Zhong YG, Rothstein JL, Petry C, Gordon SK. Depressed serum high density lipoprotein cholesterol levels in veterans with spinal cord injury. Paraplegia. 1992;30:697-703.

40. Libin A, Tinsley EA, Nash MS, Mendez AJ, Burns P, Elrod M, et al. Cardiometabolic risk clustering in spinal cord injury: results of exploratory factor analysis. Top Spinal Cord Inj Rehabil. 2013;19:183-94.

41. La Fountaine MF, Cirnigliaro CM, Emmons RR, Kirshblum SC, Galea M, Spungen AM, et al. Lipoprotein heterogeneity in persons with spinal cord injury: a model of prolonged sitting and restricted physical activity. Lipids Health Dis. 2015;14:81.

42. El-Sayed MS, Younesian A. Lipid profiles are influenced by arm cranking exercise and training in individuals with spinal cord injury. Spinal Cord. 2005;43:299-305.

43. Gorgey AS, Mather KJ, Cupp HR, Gater DR. Effects of resistance training on adiposity and metabolism after spinal cord injury. Med Sci Sports Exerc. 2012;44:165-74.

44. Staels B, Dallongeville J, Auwerx J, Schoonjans K, Leitersdorf E, Fruchart JC. Mechanism of action of fibrates on lipid and lipoprotein metabolism. Circulation. 1998;98:2088-93.

45. Nash MS, Lewis JE, Dyson-Hudson TA, Szlachcic Y, Yee F, Mendez AJ, et al. Safety, tolerance, and efficacy of extendedrelease niacin monotherapy for treating dyslipidemia risks in persons with chronic tetraplegia: a randomized multicenter controlled trial. Arch Phys Med Rehabil. 2011;92:399-410. 